\title{
Key indicator-based information system for environmental risk accounting and analysis at organizations
}

\author{
Tatyana Kostyunina ${ }^{1, *}$ \\ ${ }^{1}$ Saint Petersburg State University of Architecture and Civil Engineering, 4, Vtoraya \\ Krasnoarmeyskaya St., 190005, Saint Petersburg, Russia
}

\begin{abstract}
The paper presents a method of designing an information system for environmental risk accounting and analysis at organizations. The environmental approach in the field of production is becoming more and more relevant. It calls for accounting and assessing various types of environmental risks accompanying the activity of an organization. However, risk accounting, analysis and assessment are not possible without information support or corresponding information systems. Therefore, the issue considered in this paper is highly topical. Algorithms of environmental risk accounting and analysis are based on the method of key indicators. Using a key indicator-based information system, it is possible to automate the collection of data on events related to the environmental safety of an organization. During the design of such an information system, we developed interfaces of the main actors (user, risk coordinator, risk manager, expert, and administrator). We also implemented a data management module, a decision-making module, and a system administration module. In the long run, the system can serve as a basis for integrated environmental safety management at organizations.
\end{abstract}

\section{Introduction}

Environmental risk is the probability of an event having adverse consequences for the environment and caused by the negative impact of economic or other activities, natural or man-made emergencies [1].

Nowadays, issues of environmental risk analysis are multi-faceted and extremely important $[2,3,4]$. Management within the environmental management system of an organization shall comply with the requirements of the international standard ISO 14001:2015 [5]. One of its significant requirements for organizations is to apply system and risk-oriented approaches.

The system approach to environmental management implies the following steps of risk management at an organization:

1. Risk identification and risk significance assessment

2. Elaboration of measures to respond to significant risks

\footnotetext{
* Corresponding author: tnktn@yandex.ru
} 
3. Monitoring of measures' implementation

4. Analysis of measures' effectiveness

These steps (in particular, the first one) may be not very effective or even not possible in the absence of well-planned risk monitoring. The aim of environmental monitoring at an organization is to ensure implementation of environmental measures, rational use and restoration of natural resources, as well as compliance with the requirements of environmental law during economic or other activities of the organization [6].

The main tasks of environmental monitoring at an organization include [7]:

- environmental control in terms of physical, chemical and biological parameters in order to evaluate the level of pollution;

- generation and maintenance of databases on the state of environment components;

- identification of the main causes of pollution sources and their regulation in order to maintain permissible levels of environmental impact;

- forecast of changes in environment components at all life cycle stages of organization's facilities and products;

- $\quad$ reporting in case of a sharp increase in environmental impact (emergency, abnormal operation, etc.).

The components of an environmental monitoring system include:

- a measurement system (measurement techniques and tools);

- $\quad$ an information system (databases and databanks with technical and economic, legal, sanitary and hygienic, medical, and biological information);

- modeling and optimization systems for parameters of objects under observation.

In turn, an information system may have many components as well. In this paper, we consider a module of such an information system, performing tasks of environmental risk accounting and analysis at organizations. Algorithms of environmental data processing are based on the method of key environmental risk indicators (KERI).

\section{Classification of Key Environmental Risk Indicators (KERI)}

The indicators of environmental impact from organizations have been considered in multiples studies, however, Pakhomova et al. [8] suggested their most complete classification, which includes the following groups:

1. Indicators of environmental results

1.1. Indicators of the environmental management system

1.2. Environmental indicators of operational processes

2. Indicators of environmental conditions of activity

Each group is provided with a detailed classification. Let us consider, for example, environmental indicators of operational processes. They include:

1. Indicators of flows of raw materials, materials and energy, determined based on the input-output analysis, including:

1.1. based on input: materials for production and packaging (primary raw materials by types; total volume and volume per production unit, including package), energy (by types; total volume; efficiency);

1.2. based on output: a) products (main products and co-products; volume of recycled waste); b) environmental services with the organization's support (e.g. volume of toxic waste utilized by organization providers).

2. Organization capacity and equipment:

2.1. capacity of environmental equipment;

2.2. fuel consumption by vehicles, including those equipped with emission reduction devices;

2.3. occupied area; 


\section{4. etc.}

Other approaches to the definition and classification of an organization's environmental performance indicators can be found in papers [9, 10, 11].

Based on the analysis of multiple sources, we can conclude that developing a structure of key environmental risk indicators is a complicated task. All the more so since this structure will underlie a database developed for an information system. At each organization, this task shall be solved with account for a set of factors so as to guarantee the efficiency of such an information system in support of managerial decisions.

\section{Information System for Environmental Risk Accounting and Analysis}

As a result of pre-design analysis, we set the goals and tasks of the designed system. The main goal of the system is to ensure support when managerial decisions are developed regarding the environmental safety of an organization.

To implement the set goal, the following tasks shall be distinguished:

- collection of data on events that took place at the organization;

- consolidation of the collected data;

- classification of risk indicators;

- $\quad$ assessment of risk indicators;

- $\quad$ selection of the most significant (key) risk indicators.

The information system comprises a set of modules that automate environmental risk accounting and analysis:

- a data module that ensures entry/editing/deletion of data on events that took place at the organization;

- a decision-making module used to determine business processes responsible for potential environmental risks;

- $\quad$ a system administration module.

To cover all functions of the designed system, we created a use case diagram. A use case is represented by functional system requirements from a viewpoint of a system actor. A system actor is a role that a user plays in relation to the system. Table 1 shows a list of such actors and their functions.

Table 1. Functions of Actors in the System of Environmental Risk Accounting and Analysis.

\begin{tabular}{|c|c|c|c|c|}
\hline Administrator & Risk manager & Expert & $\begin{array}{c}\text { Risk } \\
\text { coordinator }\end{array}$ & Users \\
\hline Authorization & Authorization & Authorization & Authorization & Authorization \\
\hline $\begin{array}{l}\text { Access to user } \\
\text { account } \\
\text { Catalog } \\
\text { management } \\
\text { Employee list } \\
\text { management } \\
\text { User list } \\
\text { management }\end{array}$ & $\begin{array}{l}\text { Access to user } \\
\text { account } \\
\text { Adding an event } \\
\text { Maintaining the } \\
\text { event log } \\
\text { Indicator } \\
\text { management } \\
\text { Event } \\
\text { management }\end{array}$ & $\begin{array}{l}\text { Access to user } \\
\text { account } \\
\text { Development of } \\
\text { key risk } \\
\text { indicators } \\
\text { Evaluation of } \\
\text { consequences } \\
\text { of the } \\
\text { previously } \\
\text { added events }\end{array}$ & $\begin{array}{l}\text { Access to user } \\
\text { account } \\
\text { Adding an event } \\
\text { Maintaining the } \\
\text { event log } \\
\text { Adding an event } \\
\text { Typifying events }\end{array}$ & $\begin{array}{l}\text { Access to user } \\
\text { account } \\
\text { Adding an event } \\
\text { Maintaining the } \\
\text { event log }\end{array}$ \\
\hline
\end{tabular}

The functional system requirements are represented by a use case diagram. A fragment of such a diagram is shown in Figure 1. 


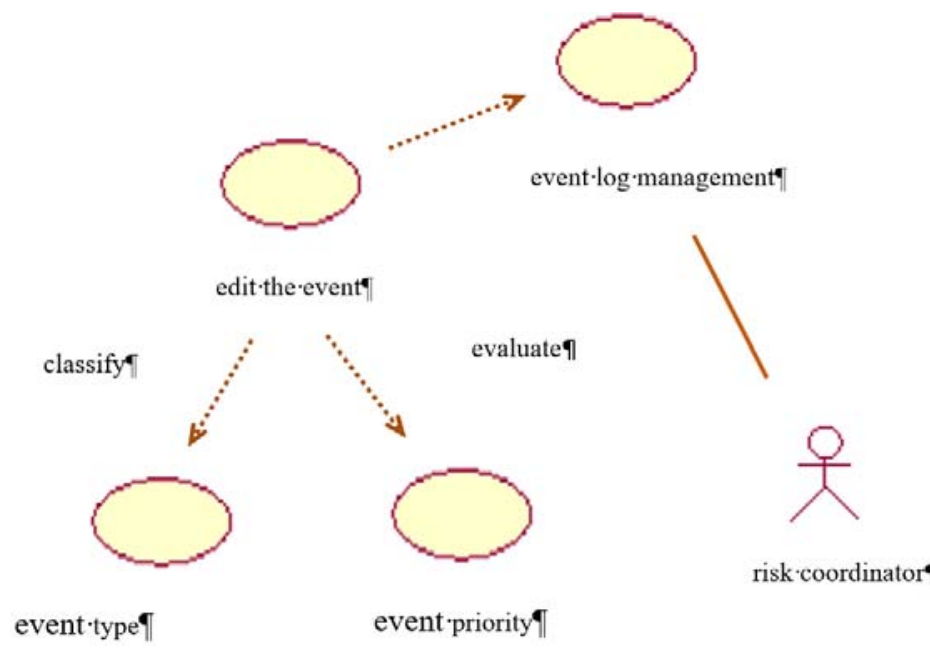

Fig. 1. Functional requirements for a risk coordinator.

The second fragment of such a diagram is shown in Figure 2.

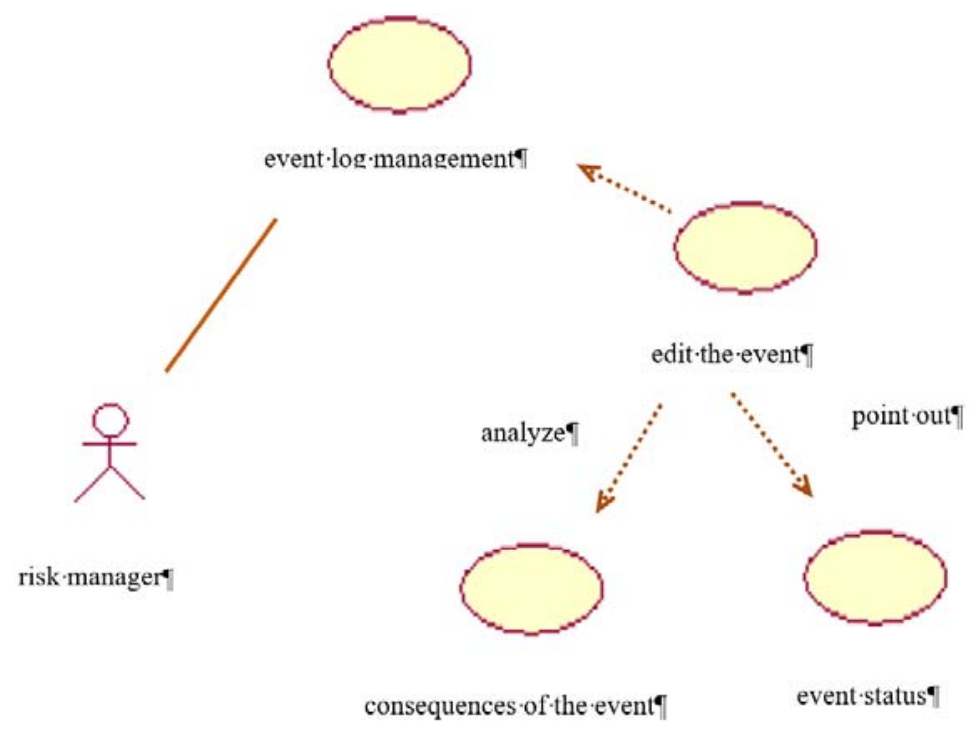

Fig. 2. Functional requirements for a risk manager.

To gain a better understanding of a task, such diagrams are usually supplemented by textual scenarios that clarify, or present details for, the sequence of actions performed by the system when implementing use cases.

Authentication is provided by the system's own mechanisms when a user enters a login and password. Then, actions described in the scenarios are performed. Table 2 shows examples of such scenarios.

Table 2. Scenario Examples.

\begin{tabular}{|l|l|}
\hline \multicolumn{1}{|c|}{ Actions } & \multicolumn{1}{c|}{ Scenarios } \\
\hline Record an event & - The system offers a form to record an event. \\
& - The user enters data on the event. \\
& - The system saves the event in the log. \\
\hline
\end{tabular}




\begin{tabular}{|c|c|}
\hline Typify the event & $\begin{array}{l}\text { - The system displays a table with the newly recorded events that } \\
\text { need to be typified. } \\
\text { - The risk coordinator chooses one of the events to be typified. } \\
\text { - The system offers a form to edit the event (with a list of types). } \\
\text { - The user selects a relevant type for the event and accepts the } \\
\text { changes. } \\
\text { - The system saves the results of editing. }\end{array}$ \\
\hline $\begin{array}{l}\text { Maintain the KERI } \\
\text { catalog }\end{array}$ & $\begin{array}{l}\text { - The system displays a table with a list of key environmental risk } \\
\text { indicators (KERI). } \\
\text { - The risk manager chooses one of the indicators to be edited. } \\
\text { - The system offers a form to edit the corresponding data. } \\
\text { - The risk manager edits the data as required. } \\
\text { - The system saves the results of editing. }\end{array}$ \\
\hline Evaluate KERI & $\begin{array}{l}\text { - The system offers a questionnaire with a list of key environmental } \\
\text { risk indicators (KERI) to be evaluated. } \\
\text { - Answering the questionnaire questions, the expert evaluates the } \\
\text { indicators. } \\
\text { - The system calculates the average score for each KERI. } \\
\text { - If the average score is higher than the set threshold, the system } \\
\text { saves the indicator. } \\
\text { - If the average score is lower than the set threshold, the system } \\
\text { deletes the indicator. }\end{array}$ \\
\hline $\begin{array}{l}\text { Maintain the event } \\
\text { catalog }\end{array}$ & $\begin{array}{l}\text { - The system displays a table with the newly recorded events. } \\
\text { - The administrator chooses one of the entries to be edited. } \\
\text { - The system offers a form to edit the corresponding data. } \\
\text { - The administrator edits the data and accepts the changes. } \\
\text { - The system saves the results of editing. }\end{array}$ \\
\hline
\end{tabular}

Based on the main tasks of the system, we developed interfaces of all the main actors. Figure 3 presents an example of the structure of content management via the risk manager interface.

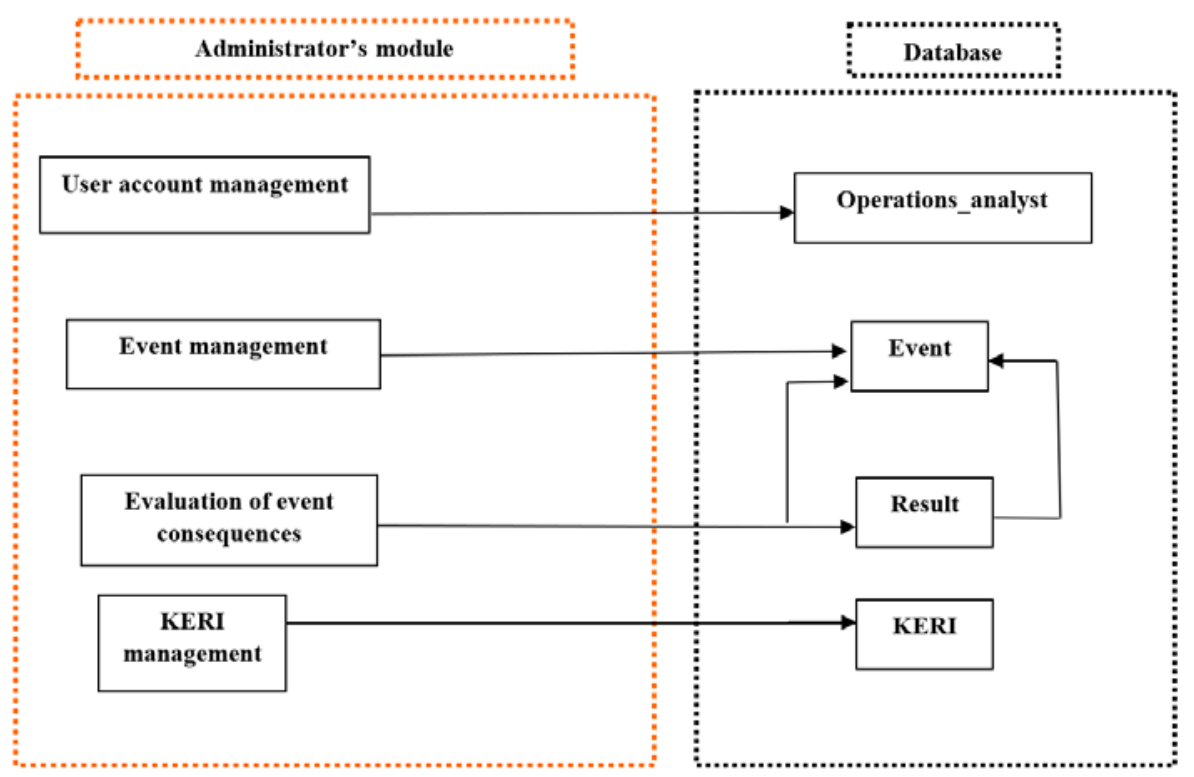

Fig. 3. Structure of content management via the risk manager interface.

Figure 4 presents an example of the structure of content management via the administrator interface. 


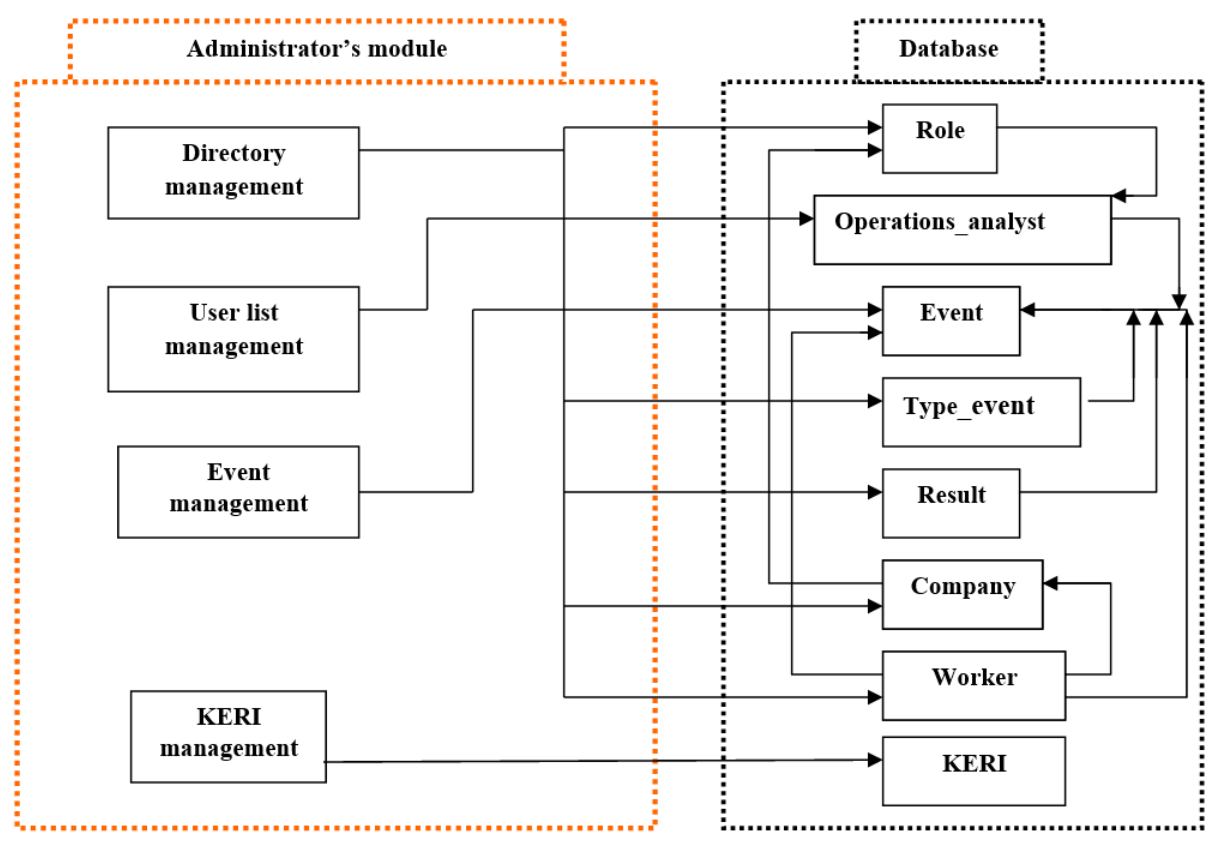

Fig. 4. Structure of content management via the administrator interface.

\section{Conclusion}

This paper considers issues of automating the monitoring of environmental risks at organizations based on key indicators. The goal of such automation is to ensure information support in making managerial decisions related to environmental safety. The issues of environmental risk management at organizations are quite significant since a wrong approach may not only result in large losses but also lead to the organization's closure.

The analysis of the subject area showed that the method of key indicators is one of the effective methods for the automation of risk monitoring. During the design of the information system, we determined functions and developed interfaces of the main actors (user, risk coordinator, risk manager, expert, and administrator). We also implemented the procedure for managing the collection and consolidation of data on financial losses of organizations as a result of environmental risks. The decision-making module provides the risk manager with the necessary information in a form of an event log and a list of key risk indicators.

Generally speaking, the development and implementation of such an information system will improve the efficiency of environmental safety management at an organization.

\section{References}

1. State Duma of the Russian Federation. Federal Law No. 7-FZ (2001) http://www.consultant.ru/document/cons_doc_LAW_34823/bb9e97fad9d14ac66df4b6 e67c453d1be3b77b4c/

2. S.A. Medvedeva, Technosphere Safety. XXI Century 1(1), 67-81 (2016)

3. O.L. Dubovik, Analysis of environmental risks in Russia. Modern Environmental Law in Russia and Abroad (2001)

4. K.A. Platonov, Vestnik of Saint Petersburg University. Sociology 1, 102-110 (2016) 
5. ISO 14001:2015. Environmental management systems (2015)

6. A.P. Khaustov, M.M. Redina, Environmental monitoring. Textbook for academic bachelor's programs. $2^{\text {nd }}$ edition (Urait, Moscow, 2019)

7. N.M. Larionov, A.S. Ryabyshenkov, Industrial ecology. Textbook and practical guide for secondary vocational education. $2^{\text {nd }}$ edition (Urait, Moscow, 2021)

8. N.V. Pakhomova, K.K. Richter, G.B. Malyshkov, A.V. Khoroshavin, Textbook for higher educational institutions (Urait, Moscow, 2020)

9. T.I. Podgornaya, Electronic Bulletin of Rostov Social and Economic Institute 3-4, 893899 (2015)

10. T.V. Danina, Ye.V. Anoshkina, Science and Modernity 1-3, 187-191 (2010)

11. V.Yu. Radoutsky, Yu.V. Vetrova, A.I. Kudinova, International Scientific Journal "Symbol of Science" 1-1, 51-53 (2016)

12. I. S. Maslennikova, L.M. Kuznetsov, Environmental management and audit. Textbook and practical guide for bachelor's and specialist's programs (Urait, Moscow, 2019) 